\title{
Association of waist and hip circumferences with the presence of hypertension and pre-hypertension in young South African adults.
}

\author{
Benedicta N. Nkeh-Chungag ${ }^{1}$, Thozama H. Mxhosa ${ }^{2}$, Papama N. Mgoduka²
}

\begin{abstract}
1. Zoology Department, Faculty of Science Engineering \& Technology,
Walter Sisulu University, PBX1, Mthatha 5117, South Africa.

2. Walter Sisulu University, PBX1, Mthatha 5117, South Africa.
\end{abstract}

\begin{abstract}
Background: Obesity is one of the most important risk factors for cardiovascular diseases (CVDs) including hypertension (HT) which is itself a risk factor for CVDs. Recent studies suggest that waist circumference (WC) may be more sensitive than Body Mass Index (BMI) in determining individual risk scores for CVDs.

Objectives: The current study aimed at investigating the influence of various anthropometric variables on blood pressure status in a group of students from Walter Sisulu University.

Methods: Informed consent was obtained from 216 male and female students from Walter Sisulu University with a mean age of $22.1 \pm 0.2$ years. Anthropometric measurements were performed for each participant. Blood pressure was measured in triplicates after 10 minutes of rest and the average computed.

Results: Just over $46 \%$ of the subjects were diagnosed with hypertension (HT) and pre-HT. The gender specific prevalence of HT/pre-HT was higher in the male (76.7\%) compared to the female (30.5\%) group. Waist circumference (WC) and total body fat (TBF) correlated significantly with blood pressure and HT/pre-HT in females but not males. ROC analysis showed that with the exception of waist-to-hip (WHR), all other anthropometric measurements and ratios studied can be used to discriminate blood pressure in young adult females not males.

Conclusion: Increased WC and HC were associated with HT and pre-HT in young adult females in the Walter Sisulu University.

Keywords: anthropometry, waist circumference, hip circumference, hypertension, pre-hypertension

DOI: http://dx.doi.org/10.4314/ahs.v15i3.27

Cite as: Nkeh-Chungag BN, Mxhosa TH, Mgoduka PN. Association of waist and hip circumferences with the presence of hypertension and pre-bypertension in young South African adults. Afri Health Sci. 2015 15(3):908-16. doi: http:// dx.doi.org/10.4314/abs.v15i3.27
\end{abstract}

\section{Introduction}

The prevalence of obesity has reached epidemic proportions in both industrialized and developing countries: urban and rural communities alike. Several studies have reported elevated blood pressure associated with increasing adiposity ${ }^{1}$. Obesity is an important primary health care problem as it is associated with many other conditions including $\mathrm{HT}^{2-4}$. Both obesity and $\mathrm{HT}$ are important risk factors for cardiovascular diseases. Obesity is generally assessed using BMI which gives infor-

\footnotetext{
Corresponding author:

Benedicta N. Nkeh-Chungag

Zoology Department,

Faculty of Science Engineering

\& Technology, Walter Sisulu University,

PBX1, Mthatha 5117, South Africa.

Email: bnkehchungag@wsu.ac.za;

Tel: + 27 (0)475311989;

Fax: +27 (0) 862062510 .
}

mation on the distribution of weight with respect to height but fails to give insight into adipose tissue distribution phenotype. Evidence gathered from several studies shows that central obesity (accumulation of fat in the abdominal area) is a greater risk factor for CVDs compared to other types of obesity ${ }^{5-7}$ hence the need to know the distribution of fat in patients to facilitate assessment of patient's risk profile for CVDs. This has led investigators to use various anthropometric measurements such as WC, HC, WHR, waist-to-height ratio (WHtR), visceral fat (VF) and total body fat (TBF) as well as skin fold thickness ${ }^{8-10}$ to establish which of these variables would show better association with CVDs or help predict risk.

The Jackson Heart Study showed a strong association between VF as measured by WC and cardiometabolic risk factors in adult African Americans even after accounting for BMI ${ }^{11}$. Importantly this team showed that though African Americans had lower VF mass than the Caucasian and Asian populations, WC was associated with higher blood pressure in African Americans but not in the other two races ${ }^{12}$. 
Cardiovascular diseases are the second most common cause of death after infectious diseases accounting for $11 \%$ of total deaths in developing countries ${ }^{13}$. Importantly, these deaths occurred mostly in the economically active sector of the population (35-65 years old). In South Africa, approximately 195 people die every day from CVD related causes ${ }^{14}$. Indeed CVDs are the second leading cause of death after HIV and accounted for up to $40 \%$ of deaths among South African adults in $2008^{15}$ compared to only $32 \%$ in the USA in $2010^{16}$. The World Health Organization has predicted that CVDs will dominate the global mortality trend in the next few years ${ }^{17}$.

Even though several studies have shown an association between anthropometric variables and the risk for CVD in many populations, very few studies have investigated the relationship between anthropometric measurements and blood pressure in young South Africa Adults ${ }^{18}$. The aim of this study was therefore to investigate the relationship between various anthropometric measurements and blood pressure in Walter Sisulu University students.

\section{Methods}

A cross sectional study was carried out on the Walter Sisulu University, Nelson Mandela Drive campus in Mthatha. Mthatha is a peri-urban community which is the feeder town for many rural localities. Participation was voluntary and the convenience sampling method was used. All participants were required to sign a consent form after the purpose of the study was explained to them. Anthropometry and blood pressure measurements were performed in the comfort of each student's room in the various student residential halls. Male and non-pregnant, non-lactating female student of Walter Sisulu University aged between 19 and 31 years old were included in the study.

\section{Height}

All participants were requested to take off all shoes and headgears for this procedure. Height was measured while the participant was standing with heels together against the stadiometer with the body held in a maximally erect position and hands placed on hips and head held in the Frankfurt plane ${ }^{19}$. Height was measured to the nearest $0.1 \mathrm{~cm}$.

\section{Waist and hip circumference measurements}

Waist and hip circumferences were measured using WHO STEPS protocol. Briefly, participants were ad- vised to stand erect with both feet together, arms at the side and not retract abdomen during measurement ${ }^{20}$. A non-elastic measuring tape was used to determine WC at the smallest diameter of the waist and $\mathrm{HC}$ at the widest diameter of the buttocks. All measurements were recorded to the nearest $\mathrm{cm}$.

\section{Weight determination}

Weight was determined using the Omron Body Composition Monitor BF511 which was calibrated to each individual's data using age, sex and height. Participants were requested to take off all heavy clothing, shoes and socks and to step with bare feet on to the equipment's feet electrodes. Weight was measured to the nearest 0.1 $\mathrm{kg}$ while participants stood with hands on the monitor's horns and held at waist level. When weight was read, participants stretched their arms forward while holding them at right angles to their bodies until the LCD screen stopped scanning. Weight, TBF, VF and BMI were automatically calculated and displayed. Bosy-Westphal, et al. ${ }^{21}$ validated this instrument as reliable for body composition monitoring ${ }^{21}$. Obesity was defined as BMI $\geq 30$ $\mathrm{kgm}-2^{22}$

\section{Blood pressure measurement}

Blood pressure was measured using the right arm for all participants after 10 minutes of rest in the seated position using a Microlife BP monitor which is accredited by the British Hypertension Society. Arm size appropriate cuffs were selected for participants. The cuff was placed and evenly tightened around the upper right arm $2 \mathrm{~cm}$ away from the elbow joint. Systolic and diastolic blood pressure as well as heart rate were automatically measured by the BP monitor. Three blood pressure measurements were taken and the average values computed. Normal blood pressure was defined as mean systolic blood pressure (MSBP) $<120 \mathrm{mmHg}$ and mean diastolic blood pressure (MDBP) $<80 \mathrm{mmHg}$, pre-hypertension as MSBP from 120-139 $\mathrm{mmHg}$ and MDBP from $80-89 \mathrm{mmHg}$ while hypertension was defined as MSBP $\geq 140 \mathrm{mmHg}$ and MDBP $\geq 90 \mathrm{mmHg}$ (Meier et al, 2013 ${ }^{23}$.

\section{Statistical analysis}

Descriptive statistics were computed for anthropometric measurements and blood pressure in the whole cohort and in sex specific groups. SPSS version 22.0 statistical software (SPSS Inc., Chicago, IL) was used to determine the relationship between MSBP and MDBP with individual anthropometric variables. Results were expressed as mean \pm sem. P-values $<0.05$ were consid- 
ered significant. Pearson's correlation coefficients were obtained from linear regression analysis of the relationship between blood pressure and anthropometric measurements. Receiver operating characteristic curves were constructed to determine the ability of anthropometric variables to discriminate high blood pressure in females and males.

\section{Results}

Two hundred sixteen participants were recruited into the study however complete data was obtained from 214 participants. The average age of participants was $22.1 \pm 0.2$ years though the females were significantly younger than males $(21.7 \pm 0.3$ yrs vs $22.9 \pm 0.4$ yrs; $\mathrm{p}<0.05)$. Females were significantly shorter and weighed less than the males (Table 1).

Table 1: Descriptive statistics of research subjects.

\begin{tabular}{|l|l|l|l|}
\hline & Whole Group & Male Subjects & Female Subjects \\
\hline No. of subjects & 216 & 74 & 142 \\
\hline Age (yrs) & $22.1 \pm 0.2$ & $22.9 \pm 0.4$ & $21.7 \pm 0.3^{*}$ \\
\hline Height (cm) & $163.5 \pm 0.6$ & $171.8 \pm 0.8$ & $159.7 \pm 0.6^{* *}$ \\
\hline Weight (kg) & $66.5 \pm 0.8$ & $68.2 \pm 1.5$ & $65.7 \pm 1.1$ \\
\hline BMI (kg/m $)$ & $25.7 \pm 0.8$ & $25.2 \pm 2.0$ & $26.1 \pm 0.6$ \\
\hline WC (cm) & $77.3 \pm 0.6$ & $76.1 \pm 1.1$ & $77.9 \pm 0.9$ \\
\hline HC (cm) & $100.1 \pm 0.8$ & $90.1 \pm 1.0$ & $102.1 \pm 1.1^{* *}$ \\
\hline Visceral fat (\%) & $5.2 \pm 0.2$ & $5.6 \pm 0.4$ & $5.1 \pm 0.3$ \\
\hline Total fat (\%) & $16.5 \pm 2.1$ & $21.3 \pm 0.9$ & $43.1 \pm 3.0^{* *}$ \\
\hline WHR & $0.84 \pm 0.08$ & $0.79 \pm 0.01$ & $0.88 \pm 0.12$ \\
\hline WHtR & $0.47+0.01$ & $0.44 \pm 0.01$ & $0.49 \pm 0.01^{* *}$ \\
\hline Mean SBP (mm Hg) & $118 \pm 1$ & $125 \pm 2^{* *}$ & $115 \pm 1$ \\
\hline Mean DBP (mm & $73 \pm 1$ & $77 \pm 2^{* *}$ & $72 \pm 1$ \\
\hline
\end{tabular}

$\mathrm{BMI}=$ body mass index; $\mathrm{WC}=$ waist circumference; $\mathrm{HC}=$ hip circumference; $\mathrm{WHR}=$ waist-to-hip ratio; $\mathrm{WHtR}=$ waist-to-height ratio; $\mathrm{SBP}=$ systolic blood pressure; $\mathrm{DBP}=$ diastolic blood pressure. ${ }^{*} \mathrm{p}<0.05 ;{ }^{* *} \mathrm{p}<0.01$.

Females tended to have higher BMI and WC compared to males though the differences were not statistically significant. Females also had significantly bigger HC $(102.1 \pm 1.1 \mathrm{~cm}$ vs $90.1 \pm 1.0 \mathrm{~cm} ; \mathrm{p}<0.01)$ and higher $\mathrm{TBF}$ $(43.1 \pm 3.0 \%$ vs $21.3 \pm 0.9 \%, \mathrm{p}<0.01)$. Although females were shorter than males, they had significantly higher WHtR $(0.49 \pm 0.01$ vs $0.44 \pm 0.01, \mathrm{p}<0.01)$ compared to males. Males on the other hand had significantly higher MSBP $(125 \pm 2 \mathrm{~mm} \mathrm{Hg}$ vs $115 \pm 1 \mathrm{~mm} \mathrm{Hg}, \mathrm{p}<0.01)$ and MDBP $(77 \pm 2 \mathrm{~mm} \mathrm{Hg}$ vs $72 \pm 1 \mathrm{~mm} \mathrm{Hg}, \mathrm{p}<0.01)$ compared to females. 
The relationship between MSBP/MDBP and various anthropometric measurements was determined using Pearson's correlation coefficients. In females, there was a moderate and statistically significant correlation between mean MSBP and BMI WC $(r=0.360)$, HC $(\mathrm{r}=0.292)$ and TBF $(\mathrm{r}=0.22)$. Mean DBP also correlated significantly but moderately with WC $(\mathrm{r}=0.216)$ and TBF $(r=0.374)$. In males on the other hand only weak and non-significant correlations were noted between mean MSBP/MDBP and all anthropometric measurements studied (Table 2).

Table 2: Linear regression between anthropometric variables and blood pressure

\begin{tabular}{|l|l|l|}
\hline \multirow{2}{*}{} & \multicolumn{2}{|l|}{ Correlation coefficients / p-value } \\
\cline { 2 - 3 } & Females & Males \\
\hline Effect of BMI on MSBP & $0.196 / 0.020$ & $0.052 / 0.661$ \\
\hline Effect of BMI on MDBP & $0.029 / 0.732$ & $0.031 / 0.792$ \\
\hline Effect & & $0.200 / 0.092$ \\
\hline Effect of HC on MSBP & $0.360 / 0.000$ & $0.136 / 0.171$ \\
\hline Effect of HC on MDBP & $0.292 / 0.000$ & $0.105 / 0.387$ \\
\hline Effect of VF on MSBP & $0.175 / 0.054$ & $0.041 / 0.736$ \\
\hline Effect of VF on MDBP & $0.003 / 0.973$ & $0.099 / 0.406$ \\
\hline Effect of TBF on MSBP & $0.220 / 0.009$ & $0.071 / 0.549$ \\
\hline Effect of TBF on MDBP & $0.374 / 0.000$ & $0.044 / 0.711$ \\
\hline
\end{tabular}

$\mathrm{BMI}=$ body mass index; $\mathrm{WC}=$ waist circumference; $\mathrm{HC}=$ hip circumference; $\mathrm{VF}=$ visceral fat; $\mathrm{TBF}=$ total fat mass. MSBP = mean systolic blood pressure; $\mathrm{MDBP}=$ mean diastolic blood pressure.

The Seventh Report of the Joint National Committee on Prevention, Detection, Evaluation and Treatment of High Blood Pressure guidelines ${ }^{25}$ were used to classify subjects as either normotensive or HT/pre-HT. A higher proportion of female compared to male sub- jects were classified as normotensive. Table 3 shows that over $53.9 \%$ of the participants $(45.8 \%$ females and $7.9 \%$ males) were normotensive while $46.1 \%$ of participants $(20.0 \%$ females and $26.1 \%$ males $)$ were HT/ pre-HT. 
Table 3: Prevalence of HT and pre-HT

\begin{tabular}{|l|l|l|l|}
\hline & Whole group & Females & Males \\
\hline Sample size & 214 & 141 & 73 \\
\hline Normotensive (n)\% & $116(54.2 \%)$ & $98(69.5 \%) \#$ & $17(23.3 \%) \#$ \\
\hline Pre-HT (n)\% & $86(40.2 \%)$ & $40(28.4 \%) \#$ & $46(63.0 \%) \#$ \\
\hline HT (n)\% & $13(6.1 \%)$ & $3(2.1 \%) \#$ & $10(13.7 \%) \#$ \\
\hline
\end{tabular}

Pre-HT = pre-hypertensive; HT = hypertensive; where pre-HT is defined as SBP of 120-139 $\mathrm{mmHg}$ or DBP of $80-89 \mathrm{mmHg}$; HT as $\mathrm{SBP} \geq 140 \mathrm{mmHg}$ and $\mathrm{DBP} \geq 90 \mathrm{mmHg}$ 25]. \# proportion of normotensive, pre-HT or HT in sex specific groups. Gender specific ratios were calculated for males and females.

Gender specific analysis showed that many more females were normotensive compared to males $(69.5 \%$ vs $23.3 \%$ ). The overall prevalence of pre-HT in the male cohort was $73.0 \%$ compared to $28.4 \%$ in females while the prevalence of $\mathrm{HT}$ was $13.7 \%$ in males compared to only $2.1 \%$ in females.
The differences in anthropometric data between normotensive and pre-hypertensive subjects were explored in Table 4. Hypertensive and pre-hypertensive participants were slightly older than the normotensive subjects. Hypertensive and pre-HT subjects had significantly higher, HC $(102 \pm 1.1$ vs $98.7 \pm 1.2)$ and BMI $(25.4 \pm 0.5$ vs $24.3 \pm 0.3)$ and $\operatorname{VF}(35.7 \pm 0.3$ vs $34.7 \pm 0.1)$.

Table 4: Comparison of anthropometric data between normotensive and HT/pre-HT subjects.

\begin{tabular}{|l|l|l|l|}
\hline & Normotensive & HT/Pre-HT & p-value \\
\hline Age $(\mathrm{yrs})$ & $21.9 \pm 0.3$ & $22.3 \pm 0.4^{* *}$ & $<0.01$ \\
\hline BMI $\left(\mathrm{kg} / \mathrm{m}^{2}\right)$ & $24.8 \pm 0.7$ & $26.9 \pm 1.5^{* *}$ & $<0.01$ \\
\hline WC $(\mathrm{cm})$ & $75.4 \pm 0.8$ & $79.4 \pm 1.1$ & $>0.05$ \\
\hline HC $(\mathrm{cm})$ & $98.7 \pm 1.2$ & $102 \pm 1.1^{* *}$ & $<0.01$ \\
\hline Visceral fat $(\%)$ & $4.8 \pm 0.1$ & $5.7 \pm 0.3$ & $>0.05$ \\
\hline TBF $(\%)$ & $35.7 \pm 0.8$ & $34.7 \pm 4.3^{* *}$ & $<0.01$ \\
\hline
\end{tabular}

$\mathrm{BMI}=$ body mass index; $\mathrm{WC}=$ waist circumference; $\mathrm{HC}=$ hip circumference; HT/pre-HT = hypertensive/pre-hypertensive. ${ }^{* *} \mathrm{p}<0.01$.

The presence of HT/pre-HT correlated moderately and significantly with WC in both females and males $(r=0.345 ; r=0.237$ respectively) while a significant moderate correlation was observed with $\mathrm{HC}(\mathrm{r}=0.323)$ and VF $(r=0.236)$ only in females. The HT/pre-HT status correlated less well with BMI even though participants with HT/pre-HT had higher BMI compared to normotensive participants (Table 5). There was a much weaker and non-significant correlation of $\mathrm{HT} / \mathrm{pre}-\mathrm{HT}$ with $\mathrm{HC}, \mathrm{VF}$ and TBF in males. 
Table 5: Correlation between HT/pre-HT and anthropometric measurements

\begin{tabular}{|l|l|l|}
\hline & \multicolumn{2}{|l|}{ Correlation coefficient/p-value } \\
\hline & Females & Males \\
\hline BMI & $0.197 / 0.019$ & $0.106 / 0.374$ \\
\hline WC & $0.345 / 0.000$ & $0.237 / 0.045$ \\
\hline HC & $0.323 / 0.000$ & $0.201 / 0.095$ \\
\hline VF & $0.236 / 0.005$ & $0.138 / 0.244$ \\
\hline TBF & $0.192 / 0.023$ & $0.037 / 0.756$ \\
\hline
\end{tabular}

$\mathrm{BMI}=$ body mass index; $\mathrm{WC}=$ waist circumference; $\mathrm{HC}=$ hip circumference; $\mathrm{VF}=$ visceral fat; $\mathrm{TBF}=$ total body fat.

Table 6 shows data obtained from univariate analysis by receiver operating characteristic curves (ROC) where the area under the curve greater than 0.5 indicates a positive predictive power while lower values show less predictive power. Indeed the AUC is a measure of the degree of accuracy in prediction. The accuracy of the test depends on how well the test separates the group being tested into those with and without the condition in question. Accuracy is measured by the area under the ROC curve (AUC) as follows: AUG of $0.90-1=$ ex- cellent; $0.80-0.90=$ good; $0.70-0.80=$ fair; $0.60-0.70=$ poor; $0.50-0.60=$ Fail test. All studied anthropometric measurements and ratios with the exception of WHR showed significant ability to discriminate higher blood pressure in young adult females. In males on the other hand only WC and WHtR had good predictive ability for higher blood pressure while TBF had only a weak predictive power. For similar data, the AUC was significantly higher in females than in males except in the case of WHR which was lower and non-significant in females compared to males.

Table 6. Receiver operated characteristic curve analysis of relationship between HT/pre-HT status and anthropometric measurements.

\begin{tabular}{|c|c|c|c|c|c|}
\hline & & AUG & SE & $95 \% \mathrm{CI}$ & p-value \\
\hline \multirow{6}{*}{ Females } & BMI & 0.777 & 0.047 & $0.685-0.870$ & 0.000 \\
\hline & WC & 0.749 & 0.047 & $0.658-0.840$ & 0.000 \\
\hline & $\mathrm{HC}$ & 0.769 & 0.047 & $0.675-0.858$ & 0.000 \\
\hline & TBF & 0.778 & 0.048 & $0.684-0.877$ & 0.000 \\
\hline & WHtR & 0.716 & 0.051 & $0.616-0.816$ & 0.000 \\
\hline & WHR & 0.594 & 0.054 & $0.488-0.700$ & 0.000 \\
\hline \multirow{6}{*}{ Males } & BMI & 0.610 & 0.067 & $0.479-0.741$ & 0.000 \\
\hline & WC & 0.676 & 0.067 & $0.553-0.799$ & 0.018 \\
\hline & $\mathrm{HC}$ & 0.620 & 0.067 & $0.489-0.752$ & 0.111 \\
\hline & TBF & 0.531 & 0.074 & $0.378-0.675$ & 0.675 \\
\hline & WHtR & 0.658 & 0.065 & $0.530-0.785$ & 0.033 \\
\hline & WHR & 0.634 & 0.066 & $0.504-0.764$ & 0.070 \\
\hline
\end{tabular}




\section{Discussion}

It is important to determine valid anthropometric measurements which may be useful for predicting obesity-related cardiovascular disease risk in young adults. In this study we demonstrated that five anthropometric measurements (BMI, WC, HC, TBF and WhtR) were more consistent in predicting CVD risk as determined by presence of $\mathrm{HT} /$ pre-HT than WHR in females while in males besides WC all the other anthropometric measurements were only weakly associated with CVD risk. Linear regression studies showed that both BMI and percentage TBF correlated only weakly with HT/ pre-HT. This observation corroborates previous findings which showed that TBF had no advantage over $\mathrm{BMI}$ and $\mathrm{WC}$ in predicting obesity related complications and metabolic conditions ${ }^{26,27}$. Indeed Desprès argued that because there is a wide range of $\mathrm{WC}$ for every BMI value, it will be simplistic to think that $\mathrm{WC}$ is a better measure of CVD risk over BMI especially given that WC may be influenced by subcutaneous or $\mathrm{VF}^{26}$. On the other hand, WC and HC correlated moderately with $\mathrm{HT} /$ pre-HT in both males and females while VF showed a moderate relationship only in females.

Unlike BMI, WC correlated strongly with both systolic and diastolic blood pressures in females while HC correlated well with Systolic blood pressure only. However, neither of these two anthropometric measurements had a strong influence on blood pressure values in males. Furthermore, TBF was modestly related to both systolic and diastolic blood pressures. Indeed Choy et al, ${ }^{28}$ showed an association between increased WC and raised blood pressure. Although several studies have shown that a larger HC is protective against HT and metabolic diseases ${ }^{29,30}$, our study showed such protection in males only while larger $\mathrm{HC}$ was associated with higher blood pressure in females. Some of these studies which showed that a large HC confers protection against CVDs also demonstrated that without controlling for BMI or WC, HC was associated with higher blood pressure in females ${ }^{33,34}$. Indeed, an Australian study $^{35}$ showed that HC was independently associated with increased risk for CVD in Aboriginal Australians, this relationship was however lost when BMI and WC were accounted for in their study population.

Waist circumference correlated well with higher blood pressure in both males and females. Waist circumference is a measure of abdominal obesity and is related to percentage abdominal fat mass. These results corrob- orate the findings of Liu et al, ${ }^{11}$ who showed a strong association between WC and cardiometabolic risk in African Americans irrespective of BMI. Indeed several studies have shown that WC may be a more sensitive predictor of CVD risk than the other measures of obesity $^{31,32}$. However, VF was also associated with higher blood pressures only in females and not males.

In our study of ROC analysis, WHR was weaker in predicting HT/pre-HT compared to WHtR which showed a significant discriminatory capacity between high and normal blood pressure in both males and females. Indeed Lee et al, ${ }^{27}$ and Tatsumi et al, ${ }^{36}$ showed that WHtR was a better predictor of CVDs in Japanese women compared to WC. These authors showed that WC and WHtR were more closely associated with metabolic risk factors than other indices of general adiposity. These authors also demonstrated the fact that there was a weak relationship between WHR and blood pressure in females. This observation could be explained by the fact that in the effect of WHR the effect of WC is often masked by the increase in $\mathrm{HC}$ which generally accompanies a big WC.

\section{Conclusion}

We found that higher waist and hip circumferences were modestly associated with the presence of HT/pre-HT in South African young adult females of African ancestry, thus highlighting the importance of weight management in the prevention of cardiovascular diseases in this population.

\section{Acknowledgements}

This work was financially supported by the South African Medical Research Council and the Walter Sisulu University Institutional grants.

\section{References}

1. Reddy KSN, Reddy KK, Sudha G. Overall and abdominal adiposity on blood pressure: consistency and evaluation of their association in an adult Indian population. J Life Sci. 2010; 2: 117-125 PubMed .

2. Jones L, Shivaji S, Cosby AG, Morgan T. Obesity, cardiovascular disease and diabetes. 2013. cited 2013 November 15. Available from: http://www. ssrc.msstate.edu/wp-content/uploads/4-obescvddiab-091510SmallestSize2.pdf

3. Bosomworth NJ. Approach to identifying and managing atherogenic dyslipedemia: a metabolic consequence of obesity and diabetes. Can Fam Physic. 2013; 59: 1169-1180 PubMed . 
4. Padwal RS, Sharma AM. Prevention of cardiovascular disease: obesity, diabetes and the metabolic syndrome. Can J Cardiol. 2010; 26 (Suppl. C): 18C-20C

5. Boden G, Salehi S. Why does obesity increase the risk for cardiovascular disease? Curr Pharm Des. 2013; 19: 5678-5683 PubMed .

6. Prassad DS, Kabir Z, Dash AK, Das BC. Abdominal obesity, an independent cardiovascular risk factor in Indian subcontinent: A clinic epidemiological evidence summary. J Cardiousc Dis Res. 2011; 2: 199-205 PubMed 7. Lee CM, Huxley RR, Widman RP, Woodward M. Indices of abdominal obesity are better discriminators of cardiovascular risk factors than BMI: a meta-analysis. $J$ Clin Epid. 2008; 61: 646-653 PubMed .

8. Qorbani M, Kleishadi R, Farrokhi-Khajeh-Pasha Y, Motlagh M, Aminaee T, Ardalan G, et al. Association of anthropometric measurements with cardiovascular risk factors and metabolic syndrome in normal-weight children and adolescents: The CASPIAN II Study. Obes Facts. 2013; 6: 483-492 PubMed .

9. Van Dijk SB, Takken T, Prinsen EC, Wittink H. Different anthropometric adiposity measures and their association with cardiovascular disease risk factors: a meta-analysis. Neth Heart J. 2012; 20: 205-218 PubMed . 10. Chen L, Peters A, Magliano DJ, Welbom TA, Wolfe R, Zimmet PZ, Tonkin AM. Anthropometric measures and absolute cardiovascular risk estimates in the Australian Diabetes, Obesity and Lifestyle (AUSBIAB) Study. Eur J Cardiovasc Prev Rehabil. 2007; 14: 740-745. 11. Lui J, Fox CS, Hickson DA, May WD, Hairstoen KG, Taylor HA. Impact of abdominal visceral and subcutaneous adipose tissue on cardiometabolic risk factors: the Jackson Heart Study. J Clin Endocrinol Metab. 2010; 95: 5419-5426.

12. Lorenzo C, Serrano-Rio M, Martinez-Larrad MT, Gabriel R, William K, Gomez-Gerique JA, Stem MP, Haffner SM. Central adiposity determines prevalence, differences of the metabolic syndrome. Obes Res. 2003; 11; 1480-1487 PubMed .

13. Jamison DT, Feachem RG, Makgoba MW, Bos ER, Baingana FK, Hofman KJ, Rogo KO. Disease and Mortality in Sub-Saharan Africa: 2nd Ed. Wahington: World Bank. 2006. p. 305-328.

14. Marendza M, Hofman KJ, Tollman SM. A hidden menace: Cardiovascular disease in South Africa and the costs of an inadequate policy response. South African Heart. 2011; 8: 48-57 PubMed .

15. BeLue R, Okoror TA, Iwelunmor J, Taylor KD, Agyemang C, Ogedegbe G. An overview of cardiovas- cular risk factor burden in sub-Saharan African countries: a socio-cultural perspective. Global Health. 2009. 5:10. cited 2012 Feb 12. Available from: http://www. ncbi.nlm.nih.gov/pmc/articles/PMC2759909/

16. National Institute for Health: National Heart, Lung and BloodInstitute. Disease Statistics. Fact book 2012. cited 2013 Nov 20. Available from: http://www.nhlbi. nih.gov/about/factbook/chapter4.htm

17. World Health Organization. World Health Statistics. 2009. Geneva. World Health Organization.

18. Smith C, Essop MF. Gender differences in metabolic risk factor prevalence in a South African student population. Cardiovasc J Afr. 2009; 20:178-82 PubMed.

19. BMI Task Team. A training manual for height and weight assessment - revised 2010. cited 2014 August 10 Available from: http://www.achi.net/BMIContent/ Documents/101007_Height_and_Weight_Measurement_Training_Manual1 with_revisions.pdf

20. WHO. WHO STEP wise approach to surveillance (STEPS). 2008; Geneva, World Health Organization (WHO).

21. Bosy-Westphal A, Later W and Hitze B. Accuracy of bioelectric impedance consumer devices for measurement of body composition to whole body magnetic resonance imaging and dual X-ray absorption. Obes Facts. 2008; 1: 319-324 PubMed .National High Blood Pressure Education Program. The Seventh Report of the Joint National Committee on Prevention, Detection, Evaluation, and Treatment of High Blood Pressure 2004; Bethesda (MD): National Heart, Lung, and Blood Institute (US).

22. WHO Expert Consultation. Waist Circumference and Waist-Hip Ratio: Report of a WHO Expert Consultation. 2011; Geneva. [cited 2013 October 23]. Available from: http://whqlibdoc.who.int/publications/2011/9789241501491_eng.pdf

23. Johnson F, Beeken R, Croker H, Wardle J. Do weight perceptions among obese adults in Great Britain match clinincal definitions: Analysis of cross-sectional surveys from 2007 and 2012. BMJ Open. 2014; 4: e005581. [cited 2015 January 30]. Available from: http://bmjopen. bmj.com/content/4/11/e005561.full

24. Meier P, Messerli F, Baumbach A, Lansky AJ. Pre-hypertension: another "pseudodisease"? BMC Medicine 2013; 11: 211-213. [cited 2015 January 30]. Available from: http://www.biomedcentral.com/content/pdf/1741-7015-11-211.pdf

25. National High Blood Pressure Education Program. The Seventh Report of the Joint National Committee 
on Prevention, Detection, Evaluation, and Treatment of High Blood Pressure 2004; Bethesda (MD): National Heart, Lung, and Blood Institute (US).

26. Desprès JP. Body fat distribution and risk of cardiovascular disease. Circulation. 2012; 126: 1301-1313 PubMed .

27. Lee K, Song YM, Sung J. Which obesity indicators are better predictors of metabolic risk? Healthy twin study. Obesity (Silver Spring). 2008; 16: 834-840.

28. Choy CS, Chan WY, Shih CC, Wu LC, Liao CC. Waist circumference and risk of elevated blood pressure in children: a cross sectional study. BMC Public Health. 2011; 11: 613 - PubMed ; 619.

29. Azizi F, Esmaillzadeh A, Mirmiran P. Larger hip circumference independently contributes to reduced risk of diabetes,hypertension and dyslipidemia in Tehranian adult women. Iranian J Endocrinology and metabolism. 6: cited 2013 Oct 24. Available from: http://www.medlib. $\mathrm{ir} /$ en-us / article/28476272/larger-hip-circumference-independently-contributed-to-reduced-risk-of-diabetes-hypertension-and-dyslipidemia-in-tehranian-adult-women(abstract)

30. Severinsen MT, Kristensen SR, Johnsen SP, Dethlefsen C, Tjonneland A, Overvad K. Anthropometry, body fat and venous thromboembolism. Circulation. 2009; 120: 1850-1857 PubMed .

31. Czernichow S, Kengne AP, Stamatakis E, Hamer $\mathrm{M}$, Batty GD. Body mass index, waist circumference and waist-hip ratio: which is the better discriminator of cardiovascular disease mortality risk? Evidence from an individual-participant meta-analysis of 82864 participants from nine cohort studies. Obes Rev. 2011; 12: 680687 PubMed.

32. Klein S, Allison DB, Heynsfield SB, Kelly De, Leibel RL, Nonas C, et al, Waist circumference and cardiometabolic risk: a consensus from shaping America's Health: Association for weight management and obesity prevention: NAASO. The Obesity Society of America: the American Society for Nutrition and American Diabetes Association. Am J Clin Nutri. 2007; 85: $1197-$ 1202 PubMed .

33. Parker ED, Pereira MA, Stevens J, Folsom AR. The atherosclerosis risk in community study. Epidemiol. 2009; 169:837-847 PubMed .

34. Heitmann BL, Frederiksen P. Thigh circumference and risk of heart disease and premature death: prospective cohort study. BMJ 2009: 339: b3292. cited 2013 Oct 14. Available from: http://www.ncbi.nlm.nih.gov/ pmc/articles/PMC2737606/pdf/bmj.b3292.pdf

35. Wand $Z$ and Hoy WE. Waist circumference, body mass index, hip circumference and waist-to-hip ratio as predictors of cardiovascular disease in Aboriginal people. Eur J of Clin Nutri. 2004; 58: 888-893 PubMed .

36. Tatsumi Y, Watanabe M, Kokubo Y, Nishimura K, Higashiyana A, Okamura T, Miyamoto Y. Effect of age on the association between waist-to-height ratio and incidence of cardiovascular disease: Situa study. J Epidemiol. 2013; 23: 351-359. 